\title{
Cervantes y el amor: evolución de las colocaciones desde la perspectiva de género
}

LORENA GARCÍA SAIZ

Institut La Talaia

Resumen: Este artículo presenta una unidad didáctica de Lengua Castellana y Literatura, que se trabaja en el Aula de Acogida de un centro de secundaria con un grupo de alumnado extranjero con un nivel B1. Concretamente, se trabajan las colocaciones amorosas aparecidas en diversas poesías de Miguel de Cervantes, mediante un conjunto de actividades guiadas y desde un enfoque comunicativo. Posteriormente, se comparan con similares construcciones en productos culturales actuales, -en este caso, con cuestionarios de revistas juveniles que giran en torno al amor-, con lo que se comprueba que muchas de las actuales concepciones sobre las relaciones amorosas tienen un bagaje histórico y temporal, construido bajo la idea del «amor romántico». Así pues, el acercamiento a la obra de uno de los mayores escritores de la literatura universal- centrándonos en el reconocimiento, composición y uso de diversas colocaciones- sirve para trabajar componentes no solo lingüísticos sino culturales, contribuyendo a una labor coeducativa.

Palabras clave: colocaciones, amor romántico, Cervantes, poesía

\begin{abstract}
This article presents a Spanish Language and Literature didactic unit that it is worked in the Shelter classroom secondary school with B1 level pupils group. In particular, this unit works with loving placements that appear in various poems of Miguel de Cervantes, through a set of guided activities in the most meaningful way. Subsequently, they are compared with similar constructions in current cultural products, -such as youth magazines questionnaires that deal with love-, which it can be checked how many of the current conceptions of love relationships have a historical and temporary background, which it has been built under the idea of «romantic love». Thus, the approach to the work of one of the world literature greatest writers -focusing on recognition, composition and use of different placements - serves to work not only linguistic but also cultural components contributing to a work coeducational.
\end{abstract}

Key words: placements, romantic love, Cervantes, poetry 


\section{Marco teórico de la actividad}

La propuesta versa sobre las colocaciones -uso, características y estructura de estas expresiones semirrígidas- y la obra de Miguel de Cervantes. Se desarrolla dentro del Aula de Acogida de un centro de secundaria, un recurso organizativo y metodológico que atiende al alumnado recién llegado al sistema educativo español ofreciéndole, por un lado, las herramientas básicas para comunicarse de manera oral y escrita y, por el otro, una acogida y atención a nivel emocional. El hilo conductor es el concepto del amor -concretamente el catalogado como «romántico»-, sobre el que se quiere aplicar una mirada de género para fomentar la igualdad en las relaciones de pareja.

Así, se acerca el yo lírico al alumnado, y se trata la obra de este escritor universal de modo general, ya que sus poesías están incluidas dentro de sus textos narrativos y teatrales. Además, se abordan las colocaciones -pieza clave en el proceso de adquisición de una lengua-, que Corpas Pastor define como

unidades fraseológicas formadas por dos unidades léxicas en relación sintáctica, que no constituyen, por sí mismas, actos de habla ni enunciados; y que, debido a su fijación en la norma, presentan restricciones de combinación establecidas por el uso, generalmente de base semántica: el colocado autónomo semánticamente (la base) no solo determina la elección del colocativo, sino que, además, selecciona en este una acepción especial, frecuentemente de carácter abstracto o figurativo

Corpas Pastor (1996: 66)

La identificación y asunción de las colocaciones crea ciertos problemas entre los estudiantes, ya que «a pesar de ser semánticamente transparentes, precisamente por no coincidir de una lengua a otra representan un escollo en el dominio del léxico por parte de aprendientes de una lengua extranjera» (Higueras García, 2004: 1).

En este sentido, los cognitivistas han demostrado que el hablante asimila el léxico a través de redes semánticas o cognitivas (Molero Perea, 2012: 607) que teje y almacena a medida que se aprende en el lexicón, de manera que cada palabra o lexema usado hace que se activen otras palabras con las cuáles tiene cierta relación. Además, Molero Perea resalta que es importante que

los docentes de ELE seamos conscientes de la manera que sabemos que se asimila léxico nuevo y por lo tanto, llevar al aula ejercicios que den cuenta de esto. Las palabras se ponen en funcionamiento en combinación con otras palabras y por tanto debemos acostumbrar y educar a nuestros estudiantes a asimilar combinaciones léxicas y no piezas aisladas

Molero Perea (2010:9)

Una manera de proceder al estudio y uso de las colocaciones es mediante su clasificación semántica -en esta propuesta didáctica en torno al amor- y, para favorecer un mejor aprendizaje, se aplica un enfoque comunicativo que, según subraya Maati Beghadid, parte de la idea de que

el significado proviene del uso, que desde su base se centra en la explotación de los aspectos comunicativos y discursivos del lenguaje, es decir, que se debe estudiar la lengua con el fin de usarla en la vida real porque es un instrumento que facilita la comunicación entre sus usuarios.

Maati Beghadid (2013:8) 
Concretamente, se trabajan las colocaciones de tipo amoroso presentes en la obra poética cervantina y, para ello, se parte de los conocimientos previos que el estudiantado tiene sobre el amor y sus características, y de sus propias experiencias amorosas, que unidos al desarrollo de las actividades de la unidad, generan reflexiones e intercambio de opiniones entre el alumnado sobre un concepto vigente, tema universal en cualquier cultura.

\section{Al respecto del amor en Cervantes, Muñoz Sánchez subraya que dicho concepto}

ocupa un lugar privilegiado en su obra, tanto que se puede tener por cierto que para ilustrarlo hubo de empaparse de no pocas lecturas, fueran estas tratados filosóficos o la mejor retórica literaria. En cualquier caso, reflexionando sobre unos y otros logró construirse su propio sistema conceptual, erigido sobre un sincretismo de sobresaliente complejidad, en el que todos los códigos preexistentes son sometidos a examen. En efecto, en la erótica cervantina es fácil discernir estratos del amor

Muñoz Sánchez (2009:6)

De fondo, se aborda la construcción cultural que se ha hecho del amor desde la literatura y otras disciplinas artísticas de la sociedad desde hace siglos, y que giran alrededor del «amor romántico». Concretamente, Pascual Fernández señala que dicho concepto

como lo conocemos es histórico y heredero del amor cortés, el amor burgués y el victoriano; se consolida en la dependencia entre hombres y mujeres, encontrando justificación en esa supuesta necesidad de complementación psicológica entre estos. De aceptación y asunción de concepción diferencial y complementaria de hombres y mujeres (definición del yo y del grupo al que pertenezco a través de la negación de unos atributos del otro) nacen los estereotipos, roles y mandatos de género cuya visibilidad en la sociedad y productos culturales, no hace más que reproducir estos esquemas desiguales en un círculo vicioso. Otro mito del amor romántico se basa en asociar la consecución del amor (completitud del ser) con la de la felicidad, haciendo del amor y la búsqueda de la otra mitad una meta vital

Pascual Fernández (2016: 67)

De hecho, Pascual Fernández (2016:67), resalta que «las dos primeras acepciones del Diccionario de la Real Lengua Española (DRAE) perfilan y reproducen algunas de estas características del mito del amor romántico, así como la causa y finalidad del amor». Concretamente, las explicaciones que da este manual son:

1. m. Sentimiento intenso del ser humano que, partiendo de su propia insuficiencia, necesita y busca el encuentro y unión con otro ser.

2. m. Sentimiento hacia otra persona que naturalmente nos atrae y que, procurando reciprocidad en el deseo de unión, nos completa, alegra y da energía para convivir, comunicarnos y crear.

En este sentido, Pascual Fernández (2016:67) pone el foco de atención en los medios de comunicación y los productos culturales, ya que «tienen un gran impacto e influencia en la construcción de identidad y subjetividad de niños y niñas» en la socialización y el aprendizaje del amor, por lo que pueden ser perpetuadores del mito del «amor romántico» $\mathrm{o}$, todo lo contrario, contribuir a redefinir dicho concepto desde la igualdad de género. Concretamente, en esta unidad se trabaja con cuestionarios de revistas juveniles que abordan diversos aspectos relacionados con el amor. 
Desde la Fundación Mujeres el ideal romántico ofrece un modelo de conducta amorosa que estipula

lo que "de verdad" significa enamorarse y qué sentimientos han de sentirse, cómo, cuándo, y con quién sí y con quién no. Es este componente cultural, descriptivo y normativo, el causante de que se desarrollen creencias e imágenes idealizadas en torno alamor que en numerosas ocasiones dificulta el establecimiento de relaciones sanas y provoca la aceptación, normalización, justificación o tolerancia de comportamientos claramente abusivos y ofensivos

Fundación Mujeres (S.f.: 7)

Por otro lado, hay que subrayar los beneficios que supone para el alumnado inmigrante conocer las colocaciones, su uso y estructura, ya que les ayuda a desarrollar la competencia sociocultural, es decir, las pautas que regulan los usos lingüísticos en función del contexto en el que se producen. Galindo Merino destaca la importancia de trabajar esta competencia en la adquisición de una segunda lengua ya que

en una sociedad como la actual, que favorece un contacto intercultural cada vez más intenso debido, entre otros, a los movimientos migratorios, la globalización, los intercambios comerciales o el turismo, se requiere la consecución de una competencia comunicativa que asegure que las producciones lingüísticas no tan solo son gramaticalmente correctas, sino adecuadas a la situación

Galindo Merino (2005:434)

La enseñanza de colocaciones en ELE queda recogida en el apartado de Nociones Generales del Plan Curricular del Instituto Cervantes (PCIC) (2007), que recoge en los inventarios del componente nocional «toda una serie de unidades léxicas pluriverbales, como colocaciones y expresiones idiomáticas».

Este Plan parte de la base de que el hablante cuenta con un amplio conjunto de bloques semiconstruidos que puede combinar al hablar, junto con unidades léxicas simples. Estas colocaciones dan pie a conocer la estructura de la combinatoria de la palabra abordada y a adaptarla dentro del proceso de aprendizaje y a modificarse con la adición de nuevos elementos.

De acuerdo al PCIC (2007), los objetivos generales se centran en el alumno como agente social, ya que con esta unidad didáctica se fomenta la participación de este en interacciones sociales dentro de la comunidad social y académica en la que se integra, el intercambio de opiniones, puntos de vista, experiencias personales, sentimientos y deseos en torno a temas de interés personal o general, la participación activa en intercambios comunicativos y la toma de iniciativas.

Al mismo tiempo, el estudiante se desenvuelve con textos orales y escritos, transfiere las ideas principales y secundarias que tienen, así como las relaciones jerárquicas que se establecen entre ellas.

Desde la óptica del alumno como hablante intercultural, se trabaja la diversidad cultural, el papel de las actitudes y los valores afectivos, los referentes culturales y las normas y convenciones sociales, entre otros aspectos.

Asimismo, dentro del apartado de gramática se trata la identificación de las categorías de palabras, algo necesario para entender la estructura de las colocaciones acorde a su tipología. 
Las funciones tratadas son: pedir y dar opinión, expresar aprobación y desaprobación, posicionarse a favor o en contra, preguntar si se está o no de acuerdo, expresar acuerdo y desacuerdo, mostrar escepticismo, expresar certeza y evidencia o lo contrario y expresar conocimiento o desconocimiento.

Respecto a los géneros discursivos y productos textuales se tienen en cuenta, dentro del apartado de la transmisión oral, las conversaciones cara a cara informales y formales, sobre temas de interés personal -experiencias personales, sentimientos, opiniones,...- y temas abstractos. Este espacio se trabaja desde la producción y la recepción de los intercambios comunicativos. En cuanto a la comunicación escrita, se aborda desde la recepción de poemas y cuestionarios y la producción de textos líricos. Al mismo tiempo, está presente el trabajo con las macrofunciones descriptiva, narrativa, expositiva y argumentativa.

En cuanto a habilidades y actitudes interculturales, se abordan las relacionadas con la configuración de una identidad cultural plural mediante la aproximación cultural, la percepción de diferencias culturales, la interacción y la mediación.

Por otro lado, las colocaciones se trabajan en Educación Secundaria Obligatoria (ESO) teniendo en cuenta lo dispuesto en la Ley Orgánica 8/2013, de 9 de diciembre, para la Mejora de la Calidad Educativa (LOMCE). Concretamente, en el apartado Conocimiento de la lengua, la normativa insiste en «la interpretación adecuada, con ayuda del diccionario, del lenguaje proverbial (refranes, modismos,...)», es ahí donde tienen cabida el acercamiento y profundización de dichas estructuras semirrígidas. Dentro del repaso a la historia de la literatura española, el Barroco y la figura de Cervantes forman parte de la lista de épocas literarias y autores que se deben conocer.

Los objetivos de esta unidad didáctica son reconocer y usar correctamente las colocaciones, conocer las principales características de la obra cervantina, entender el mensaje del yo poético, expresarse con coherencia, cohesión y adecuación, mejorar la comprensión y expresión escrita y oral, la interacción y mediación, argumentar de forma clara y concisa, promover una conciencia crítica y fomentar la interculturalidad y la igualdad de género. Además, el alumnado trabaja y adquiere destrezas de las siguientes competencias básicas: lingüística y audiovisual, social y ciudadana, autonomía e iniciativa personal y aprender a aprender.

\section{Desarrollo de la unidad didáctica}

La unidad aborda el concepto de «amor romántico» a través del reconocimiento de las colocaciones amorosas que aparecen en diversos extractos de las composiciones poéticas de Miguel de Cervantes. Posteriormente, se comparan con productos culturales recientes -cuestionarios de revistas juveniles sobre el amor-para comprobar si dicho tipo de estructuras semirrígidas se encuentran presentes actualmente.

De fondo y como hilo conductor, se aborda la visión que nuestra sociedad tiene del amor, lo que ayuda a destapar el trasfondo patriarcal que lo rige y que crea relaciones desiguales que pueden desembocar en situaciones de violencia de género. Por ello, desde una mirada crítica, se busca la sensibilización y la prevención ante esas situaciones para fomentar el cambio. 
A lo largo de 5 sesiones de una hora de duración cada una, el alumnado profundiza en los anteriores conceptos y acaba por crear una composición poética desde una mirada coeducativa en la que hace uso de colocaciones amorosas como producto final en la que se deconstruye el concepto de «amor romántico».

Respecto a la metodología, un alto porcentaje de actividades se realizan por parejas o grupo, que supone un camino preparatorio para el desarrollo de la tarea final. Al inicio de cada nueva sesión, el profesor recapitula los contenidos tratados anteriormente y resuelve nuevos interrogantes de los estudiantes tras las explicaciones y la resolución de ejercicios, para que haya un continuo flujo de información entre docente y aprendiente que le ayude en la (auto) evaluación continua del día a día.

En el plano de la evaluación, los criterios que se deben tener en cuenta son la observación diaria del docente hacia el alumnado es clave mientras realiza actividades para consolidar los contenidos. Finalmente, hay una evaluación del producto final por parte del docente y una coevaluación entre el alumnado, todo ello mediante el uso de rúbricas. Los aspectos que se valoran son el vocabulario y las colocaciones usadas, el dominio del contenido y las estructuras tratadas, la organización del texto lírico, el trabajo cooperativo y la interacción.

En la primera sesión se realiza una lluvia de ideas alrededor del concepto «amor romántico» para recoger los conocimientos previos de dicho concepto y reflexionar desde una mirada coeducativa sobre los mitos que giran alrededor de este.

Al mismo tiempo, se presenta «amor romántico» como una colocación, lo que sirve para explicar su definición, características y tipos, siguiendo la clasificación propuesta por Koike:

1. Lista de colocaciones según Koike (2001) y ejemplos:

a. Sustantivo + verbo (o viceversa)/adjetivo:

(1) el ánimo decae / saciar el hambre, sentirse cansado

b. Sustantivo + de + sustantivo:

(2) color de rosa

c. Verbo + adverbio/ adjetivo:

(3) limpiar concienzudamente, estar distraído

d. Verbo + locución nominal /adverbial:

(4) prestar gran atención, mear fuera del tiesto

e. Locución verbal + sustantivo:

(5) llevar a cabo un proyecto

f. Sustantivo + locución adjetival:

(6) salud de hierro

g. Adjetivo + locución adverbial:

(7) alto como un pino 
Posteriormente, se procede a la realización y corrección de ejercicios para la identificación de este tipo de estructuras semirrígidas. Por un lado, deben explicar la estructura de la colocación amorosa y el significado de las siguientes expresiones:

(8) Estar enamorado hasta los huesos

(9) Tener un flechazo

(10)Estar colgado por alguien

(11)Tener un amor platónico

En la misma línea que la actividad anterior, el alumnado debe leer las 19 afirmaciones que el Proyecto de Investigación DETECTA 2011 sobre Sexismo y Violencia de Género en la juventud andaluza e Impacto de su exposición en menores ha aglutinado en cuatro grupos mitos sobre el «amor romántico» ${ }^{1}$ : Grupo 1. El amor todo lo puede; grupo 2: El amor verdadero predestinado; grupo 3: El amor es lo más importante y requiere la entrega total y grupo 4: El amor es posesión y exclusividad. Por parejas, además de comentar el significado de cada aseveración, deben tratar de identificar colocaciones amorosas tales como:

(12) Cambio por amor

(13) Omnipotencia del amor

(14) Amor «verdadero»

(15) Pasión eterna

(16) Entrega total

En las dos siguientes sesiones se aborda la obra de Cervantes a través de la lectura de varios de sus poemas. Primero el docente explica características generales del autor y el contexto (Barroco) y, a continuación, los rasgos principales de la obra a trabajar, se lee el extracto poético seleccionado incluido en esa obra, se habla de su sentido general y, finalmente, el alumnado por parejas, localizan y ponen en común las colocaciones amorosas halladas en cada una de esas creaciones.

Concretamente, se trabajan extractos de novela pastoril La Galatea (1585), -diversos extractos de Elicio, Galatea y Timbrio, que aparece en diversos momentos de las tres partes de la obra-, en los que aparecen colocaciones como:

(17) Encender el alma

(18) Fuego que consume / quema

(19) Tener en la gloria

(20) Abrir el pecho

(21) Amor que abrasa/ aprieta/ enfría/ hiere

(22) Red de amor

(23) Arder en amoroso fuego

\footnotetext{
${ }^{1}$ Las afirmaciones con las que se trabaja sobre el «amor romántico», recogidas en cuatro grandes apartados o mitos, están disponibles en Fundación mujeres. (Sin fecha). Mitos del amor romántico y prevención de la violencia de género. (Sin fecha). Coeducación y mitos del amor romántico, 93, 7-10.
} 
En el caso de las Novelas ejemplares, se trabajan estas estructuras fijadas por el uso con las composiciones que aparecen en La Ilustre Fregona (1613). Entre las colocaciones encontradas destacan:

(24) Amor inmortal

(25) Causa de mi mal

La obra de Don Quijote de la Mancha se acerca a los alumnos de modo general, y se trabajan las colocaciones con el Ovillejo de Don Quijote en el capítulo XXVII de la primera parte de esta novela, escrita en 1605. Estas son:

(26) matar la esperanza / desdenes / celos / ausencia

(27) causar dolor

(28) consentir el duelo

(29) curar la pasión

La cuarta sesión realiza un salto temporal, ya que se procede a la lectura y localización de colocaciones amorosas en productos culturales actuales. Concretamente, se hace a través de un conjunto de cuestionarios sobre el tema del amor que aparecen en diversas revistas juveniles. El alumnado tiene que realizar cada test, localizar las estructuras semirrígidas amorosas que aparecen y, posteriormente, conocer los resultados de cada test y ponerlos en común, primero por parejas y más tarde en gran grupo. De este modo se consigue, por un lado, el reconocimiento de colocaciones y, por otro lado, la reflexión posterior global sobre el «amor romántico» y el mantenimiento de este mito cuatrocientos años después de la obra de Cervantes.

En la revista Cosmopolitan, en el cuestionario ¿Cómo eres en el amor $?^{2}$ se localizan estas colocaciones amorosas

(30) chasco sentimental

(31) relación ideal

(32) hacerse ilusiones

(33) relación estable

(34) rollo de una noche

En el caso de la publicación juvenil Superpop, el test ¿Estás enamorada de verdad? ${ }^{3}$, Se localizan las siguientes colocaciones:

(35) sentir un cosquilleo

(36) amor a primera vista

(37) comer a besos

2 Disponible en https://www.cosmopolitantv.es/noticias/10700/test-icomo-eres-en-el-amor [Consulta: 29/04/2017]

${ }^{3}$ Disponible en https://www.superpop.es/test/super-test-estas-enamorada-verdad/ [Consulta: 29/04/2017] 
(38) sentir mariposas

(39) romper el corazón

(40) enamorar de verdad

En esta revista, en el cuestionario ¿Estás preparada para un nuevo amor? ${ }^{4}$, aparecen otras colocaciones como:

(41) amor de verano

(42) chico (chicarrón) ideal

(43) nuevo amor

La última sesión se dedica a la realización por parejas de un producto final que consiste en la creación de un poema que cuente con colocaciones amorosas alternativas a las trabajadas o que se dispongan de tal manera que el mensaje final sea el canto a un amor libre de prejuicios y desigualdades por razón de sexo. Finalmente, se procede a la lectura en voz alta y reflexión final entre todo el alumnado.

\section{Conclusiones}

El alumnado del Aula de Acogida aprendió a identificar e intuir colocaciones e interiorizar parte de la dinámica de su uso y su estructura. También conoció más a fondo a Cervantes, su contexto y algunos datos de sus obras más relevantes, reflexionó sobre el constructo cultural -en este caso, el «amor romántico»-, deconstruyó imágenes preestablecidas como elementos supuestamente «naturales» y construyó y redefinió conceptos que repercuten en lo sociocultural y personal. Al mismo tiempo, se tradujo en un aumento de la sensibilización hacia los temas tratados, fomentada desde el diálogo y la reflexión desde una mirada coeducativa con carácter intercultural.

Esta unidad abre la puerta para seguir ahondando en el concepto de las colocaciones en un nivel de profundidad mayor y ampliar el estudio de la paremeología y la fraseología hacia otros campos como los refranes, las frases hechas o las locuciones, entre otros aspectos. También se puede seguir vinculando con obras representativas de la literatura española y con elementos de carácter experiencial y vivencial, de modo que haga atractivo y significativo para los estudiantes los contenidos tratados, de la mano de la reflexión sobre valores con carácter universal, como se ha mostrado a través de esta unidad didáctica aglutinadora de esos conceptos.

\section{Bibliografía:}

Cervantes SaAvedra, M (1605,1615). Don Quijote de la Mancha. Recuperado el 27/4/17, de http://cvc.cervantes.es/literatura/clasicos/quijote/indice.htm

\footnotetext{
4 Disponible en https://www.superpop.es/test/estas-preparada-para-un-nuevo-amor/ [Consulta: 29/04/2017]
} 
Cervantes SAAVEdRA, M (1585). La Galatea. Recuperado el 27/4/17, de http://www.cervantesvirtual.com/obra-visor/la-galatea--1/html/ff48f142-82b1-11dfacc7-002185ce6064_61.html.

Cervantes SaAVEDRA, M (1590-1612). Novelas ejemplares. Recuperado el 27/4/17, de $\mathrm{http}: / / \mathrm{www} . c e r v a n t e s v i r t u a l . c o m /$ obra-visor/novelas-ejemplares--0/html/.

Corpas Pastor, G. (1996). Manual de fraseología española. Madrid: Gredos.

FundACIÓN MUJERES. (Sin fecha). «Mitos del amor romántico y prevención de la violencia de género», Coeducación y mitos del amor romántico, 93, 7-10. Recuperado http://www.fundacionmujeres.es/files/attachments/Documento/46001/image/_BOLETI N\%20FM\%2093.pdf.

Galindo Merino, M. (2005). «La importancia de la competencia sociocultural en el aprendizaje de las segundas lenguas». Interlingüística, 16 (1), 431-441. Recuperado el 29/8/2017, de https://dialnet.unirioja.es/descarga/articulo/2514240.pdf.

Higueras García, M. (2005). «Necesidad de un diccionario de colocaciones para aprendientes de ELE». En Castillo Carballo, M. ${ }^{a}$ A. (Coord.), Las gramáticas y los diccionarios en la enseñanza del español como segunda lengua, deseo y realidad (pp. 480-490). Recuperado el 30/4/2017, de

http://cvc.cervantes.es/ensenanza/biblioteca_ele/asele/pdf/15/15_0478.pdf.

Instituto Cervantes (2007). Plan curricular del Instituto Cervantes (PCIC).

Recuperado el $30 / 4 / 2017$, de http://cvc.cervantes.es/Ensenanza/biblioteca_ele/plan_curricular/default.htm.

KoIKe, K. (2001). Colocaciones léxicas en el español actual: Estudio formal y léxicosemántico. Alcalá de Henares: Servicio de publicaciones de la Universidad de Alcalá.

MaAti Beghadid, H. (2013). «El enfoque comunicativo, una mejor guía para la práctica docente». En Instituto Cervantes de Orán, Actas del IV Taller "ELE e interculturalidad" $\quad$ Recuperado el 25/8/2017, de https://cvc.cervantes.es/ensenanza/biblioteca_ele/publicaciones_centros/PDF/oran_2013 /16_beghadid.pdf.

Ministerio DE EdUCACIÓN (9/12/2013). Ley Orgánica 8/2013, de 9 de diciembre, para la mejora de la calidad educativa (LOMCE). Recuperado el 30/4/2017, de http://www.boe.es/boe/dias/2013/12/10/pdfs/BOE-A-2013-12886.pdf.

Molero Perea, C. y Salazar, D. (2010). «Ejercicios prácticos para trabajar las colocaciones léxicas en el aula de ELE». En Istituto Cervantes de Bruselas, Actas del I Encuentro Internacional de profesores de ELE. Recuperado el 30/4/2017, de http://cvc.cervantes.es/ENSENANZA/biblioteca_ele/publicaciones_centros/PDF/brusel as_2012/10_molero_salazar.pdf.

Molero Perea, C. (2012). «La adquisición del léxico en el aula de E/LE en contextos multilingües: la teoría de las colocaciones léxicas como solución a las interferencias léxicas». En Plurilingüismo y enseñanza de ELE en contextos multiculturales. Actas ASELE XXIII. Recuperado el 30/4/2017, de http://cvc.cervantes.es/ensenanza/biblioteca_ele/asele/pdf/23/23_0061.pdf.

Muñoz SÁnchez, J. La reescritura en Cervantes: el tema del amor. Tesis doctoral. Recuperado el 25/8/2017, de https://repositorio.uam.es/handle/10486/338. 
Pascual Fernández, A. (2016). «Sobre el mito del amor romántico. Amores cinematográficos y educación», Dedica, Revista de Educaçao e Humanidades, 10, 63$78 . \quad$ Recuperado

el 25/8/2017,

de https://dialnet.unirioja.es/servlet/articulo? codigo $=5429358$. 